\title{
Trials and tribulations
}

\author{
Vincent T DeVita Jr
}

It may be apparent from my most recent editorials that, in my opinion, cooperative oncology groups around the world rarely use the inductive reasoning process. In the midst of a molecular revolution the main instrument for translating research findings from the laboratory to the clinic is not functioning efficiently. When designed properly, clinical trials can address fundamental questions. The design of a good therapeutic experiment should be driven by knowledge of the biology and natural history of the disease.

I envisage a group of cancer cells sitting in a corner laughing hysterically at some of our approaches to experimental design. Surgeons willing to study only the operation they were trained to do; medical oncologists always giving chemotherapy on days 1 and 8 because that's when we have clinics; radiation oncologists giving treatments for only 5 days a week because it is difficult to work at weekends. Often none of the above is willing even to participate in a trial unless assured of being part of the outcome. Cancer cells don't think that way.

When involved in oncology therapeutic research, you should always have in mind the five most important questions that can be addressed in clinical trials relevant to the oncology field. It is important to know and use the most appropriate human model system to address these questions. Of course there are no clinical groups organized to do this, but there should be. Most groups specialize in studying a particular disease, or a particular stage of a disease. These groups should always have in mind the five most important questions that can be addressed in a clinical trial in that disease, or in that stage of the disease. The
If you want to really protect the interests of patients with cancer, for every trial you are asked to review, ask yourself where is the hypothesis?

VT DeVita Jr is the Editor-in-Chief of Nature Clinical Practice Oncology.

Competing interests

The author declared no competing interests.

www.nature.com/clinicalpractice doi:10.1038/ncponc1182 questions posed should not be limited to those relevant only to a particular specialty.

How do you discern the most important questions of the day? Any individual or group responsible for a clinical trials program ought to periodically participate in state-of-the-art exercises in which experts are asked to define the major questions. These experts should not be limited to one's own group. The questions would, therefore, apply to anyone anywhere who is studying the disease in question. Each research group would then be unique only in the resources it can bring to bear on addressing a question. This approach would foster fewer individual-group and more intergroup studies. The larger the group involved, the less tendency there is to proceed with this kind of exercise.

Research groups become attached to their own specialties or their own studies. Their focus is sometimes not on the best way to address important therapeutic questions but rather on the best way to prove that their approach is superior to someone else's. There is also a tendency for groups to perform studies that address lessimportant questions so that they can conduct a clinical trial for each disease or stage of a disease that falls within their purview. This is useful as a measure of the activity of a group when we review each other's grants. There is a myriad of regulatory agencies and committees that enforce burdensome regulations ostensibly to protect patients, but little effort is spent on assuring that a clinical trial is really addressing a fundamental question. If you want to really protect the interests of patients with cancer, for every trial you are asked to review, ask yourself where is the hypothesis? And, will the proposed study test it or try to confirm it? 